\title{
FOOD SAFETY KNOWLEDGE AMONG SOME WOMEN IN
}

\section{ALEXANDRIA}

\author{
Naglaa F. Gomaa*
}

\begin{abstract}
Poor food handling practices in the home are likely the cause of gastroenteritis. This study interviewed 105 Egyptian women to see how often reported practices met public health food safety recommendations. Face to face interviews were conducted asking respondents about aspects needed during the flow of food through the operation, including; sanitation, food purchasing and food preparation and serving. Results showed that $60.00 \%$ of respondents didn't wash hands throughout preparation, $30.76 \%$ of them didn't cover hair while preparing food, $55.23 \%$ of them exposed refrigerated food to temperature abuse because of frequent opening of the refrigerator door during food preparation and 64.61 did not wash utensils between food preparation. Regarding food purchasing, $60.00 \%$ of respondents could buy from unclean stores, $30.76 \%$ continued purchasing although the improper cleanliness of the food handler, $43.07 \%$ preferred low price rather than good quality foods. Although many respondents knew the characteristics of good quality food, $42.00 \%$ of them could buy non-refrigerated meat and $78.46 \%$ could buy fish not surrounded by ice crystals. For food preparation and serving, $42.85 \%$ of respondents thawed food improperly by leaving it at ambient kitchen temperature, $80.95 \%$ of subjects held food at room temperature up to or more than one hour, 86.15 cooled foods by leaving it covered on the stove, and $40.00 \%$ and $45.00 \%$ of them just warmed prepared food for reheating and reheated it more than once, respectively. People preparing food in the home need to be reminded of the increased risk of disease that can arise from poor food handling practices.
\end{abstract}

\section{INTRODUCTION}

Epidemiological studies indicate that are not reported to the public health sporadic cases and small outbreaks in authorities and receive scant attention by the homes comprise most of the food news media. Many consumers remain poisoning cases in the USA.(1) In England unaware that home is a likely place for food and Wales it is estimated that at least 60 safety problems, believing that the percent of the food poisoning that occurs is responsibility lies instead with food

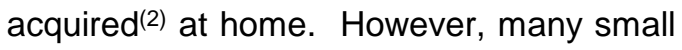
manufactures or restaurants. ${ }^{(3,4)}$ Previous outbreaks of food poisoning arising at home research, indicates that consumers generally:

\footnotetext{
*Food Hygiene and Control, High Institute of Public Health-Alexandria University, Egypt
} 
lack awareness of the dangers of storing food at the wrong temperature; ${ }^{(5,6)}$ lack knowledge about correct refrigerator temperatures; $(7,8)$ tend not to associate storage duration with the risk of food borne disease. ${ }^{(5,6)}$ and often pay little attention to "use by" dates. ${ }^{(7,8)}$ In a study examining how often reported practices in Australian homes met public health food safety recommendations, nearly every household (99.0\%) reported handling food in a way that could cause food to become contaminated. ${ }^{(9)}$ This study aimed to assess the knowledge of food safety among some women in Alexandria to see how often reported practices met public health food safety recommendations.

\section{MATERIAL and METHODS}

A structured questionnaire to collect data on the food safety knowledge of 105 women was used. In order to overcome problems from bias and from women to claim to use hygienic food handling procedures most of the time, face to face interviews were conducted within the whole target sample and data were collected from women in their own homes. Samples covered different zones in Alexandria Governorate and different groups of age and education. Also, different options (answers) for each question in the questionnaire were given to respondents to avoid leading answers when yes/no are used only as options. In the structured questionnaire, respondents (women) were asked about the safe practices during the flow of food through the operation according to the Certification Course Book of The Educational Foundation of the National Restaurant Association(10) . It covered aspects of sanitation, food purchasing as well as food preparation and serving parameters.

Sanitation was evaluated by asking respondents about personal hygiene (hair covering, and hand washing). Also, by asking respondents about correct functioning of refrigerator, cleaning of 
utensils, the use of wiping cloths, purchasing parameter was 85 points, while ventilation, and waste disposal.

that for food preparation and serving was 65

Purchasing safe food was evaluated by asking respondents if they notice the cleaning of the market/super market they used to buy from, if they notice the food handler, about the sequence for purchasing food, if food quality is a condition for purchasing and if different types of food examined for quality before being purchased.

points. The total score of respondents within each parameter was then converted into percentages. Respondents were divided into 5 groups according to their age: $20-30,31$ $40,41-50,51-60$, and $>60$ years of age. They were also divided into 4 educational groups; high (faculty graduate), medium (2 years of education after school), low (school graduate) and absent (read and write). Then

Protection of food in preparation and serving was evaluated by asking respondents about time of food preparation, methods of thawing, cooking, cooling, temperature of storing prepared food, use of leftovers and reheating.

Correct answer of each question of the interview questionnaire was given 5 points. If more than one answer was given to each question (this was frequent among respondents), 1 point was deleted for each wrong answer. Hence the total score for sanitation parameter was 65 points, that for respondents within age and educational groups were compared statistically according to their food safety knowledge.

\section{RESULTS AND DISCUSSION}

Information on public awareness of food safety at home has been gathered almost exclusively by means of questionnaire surveys (Ackerley, 1990; FDF, 1996; MAFF, 1988; Spriegel, 1990; Walker, 1996). ${ }^{(11-15)}$ Spriegel (1990) found that consumers exhibited a high degree of awareness of safe food storage, a MAFF survey (1988) found that most of the public 
recognized the dangers associated with the storage and preparation of food, and an FDF survey (1996) found that most consumers were fairly to very confident, when buying food, that they had enough information about storage, preparation, and cooking in order to keep it safe and that they claimed to always or usually follow hygiene rules carefully and keep everything clean. The results of the present investigation, which attempted to measure food safety knowledge at home, support some of the findings of these surveys.

\section{Sanitation}

\section{Hand washing}

MAFF (1991) has advised consumers that the most important precaution against food poisoning is to wash hands with soap in warm water before touching food.(16) The FDF surveys (1993) found that almost all consumers report that they always wash hands ${ }^{(17,18)}$ before handling food. In this study, $12.38 \%$ said that there is no need to wash hands before preparation because hands will be washed while washing the food to be prepared (Table 1).

Table 1: Incidence of sanitation malpractices

\begin{tabular}{|l|l|c|}
\hline \multicolumn{1}{|c|}{$\begin{array}{c}\text { Sanitation } \\
\text { Parameter }\end{array}$} & \multicolumn{1}{|c|}{ Behavior } & $\begin{array}{c}\text { Occurrences } \\
\text { (\%) }\end{array}$ \\
\hline \multirow{4}{*}{ Personal hygiene } & Hair not covered while food preparation & 30.76 \\
\cline { 2 - 3 } & Hand not washed before handling food & 12.38 \\
\cline { 2 - 3 } & Hand not washed throughout food preparation & 60.00 \\
\cline { 2 - 3 } & Wiping cloths used & 6.15 \\
\hline \hline \multirow{4}{*}{$\begin{array}{l}\text { Storage of chilled } \\
\text { foods }\end{array}$} & $\begin{array}{l}\text { Refrigerated food subjected to temperature } \\
\text { abuse (refrigerator's door frequently opened) }\end{array}$ & 55.23 \\
\cline { 2 - 3 } & Covered refrigerator 's shelves & 4.44 \\
\cline { 2 - 3 } & Refrigerator temperature not checked & 26.66 \\
\cline { 2 - 3 } & Refrigerator cleaning not frequent & 4.61 \\
\cline { 2 - 3 } & Food not covered inside refrigerator & 3.07 \\
\hline \hline \multirow{3}{*}{ Ventilation } & $\begin{array}{l}\text { Kitchen window not opened during food } \\
\text { preparation }\end{array}$ & 9.23 \\
\hline \hline \multirow{2}{*}{$\begin{array}{l}\text { Equipment and } \\
\text { utensils }\end{array}$} & Utensils not washed between preparation & 64.61 \\
\hline \hline Waste disposal & Cross contamination from utensils & 21.53 \\
\hline \hline
\end{tabular}

Note: Number of subjects $=105$ 
A higher percentage $(66.00 \%)$ was observed in another study, where subjects neglected to wash their hands when starting food preparation. ${ }^{(19)}$ More than half of respondents $(60.00 \%)$ said that they don't wash hands throughout food preparation process. A smaller minority were seen not to wash their hands at any stage throughout the food preparation process. ${ }^{(19)}$ Wiping cloths were said to be used by $6.15 \%$. Hands wiped on dish-cloth, tea towel or aprons increases the opportunities for cross-contamination. ${ }^{(19)}$

\section{Storage of chilled foods}

Previous surveys of the public have revealed that knowledge of the correct storage often for chilled foods is not widespread. The lack of thermometers in domestic refrigeration, and the consequent inability to measure the operating temperature are also well documented.(14,17) Over half of the subjects in this study opened the refrigerator door frequently during food preparation. A small percentage only (26.66\%) said that they don't check refrigeration temperature and almost all respondents claimed to have knowledge about keeping refrigerator safe and sanitary as only $4.44 \%$ covered refrigerator's shelf, $4.61 \%$ didn't clean the refrigerator frequently, and $3.07 \%$ kept food uncovered inside the refrigerator (Table 1). Others found that food was inappropriately located in the refrigerator by $81.2 \%$ of respondents, ${ }^{(9)}$ and that less than one-fourth claimed to know the temperature in their own refrigerator. ${ }^{(20)}$ But most of observed participants didn't measure their refrigerator temperature.(21)Keeping refrigerators at a temperature too warm will not inhibit the growth of microorganisms including Escherichia coli. ${ }^{(22)}$

\section{Equipment and utensils}

Cross-contamination of food can be reduced or prevented if equipment and surfaces used for both raw and cooked food are thoroughly cleaned and 
disinfected between operations. ${ }^{(16)}$ In this study, $64.61 \%$ of respondents said that they didn't wash equipment and utensils between food operations. They said that washing is done at the end of food preparation and sometimes before and after food preparation. This might increase the risk of cross-contamination especially that $21.53 \%$ of them said that they can prepare more than one food dish at the same time (Table1).

\section{Purchasing}

Results in table 2 showed that a considerable number of the respondents prepared unwholesome meals. This is seen as $60 \%$ of them preferred low price stores or these that they are used to buy from but not because it is clean. Clean environment means sanitary food. Many breakdowns in sanitation are caused by facilities that are simply too hard to keep clean. ${ }^{(10)}$ Also, $30.76 \%$ of them continue purchasing from food handlers with poor personal cleanliness. It is known that good personal cleanliness is a critical protective measure against food borne illness. ${ }^{(10)}$ In addition, $49.52 \%$ of respondents lack knowledge about the safe order of purchasing-dry and plant food first, then chilled and frozen food items. The advice from $\operatorname{MAFF}^{(16)}$ is to take chilled and frozen food home quickly, chilled and frozen ingredients should be held under chilled and/or frozen conditions until they are given to the subjects (respondents) at the end of their shopping trips. Otherwise, these foods might be exposed to temperatures conducive to bacterial growth $^{(19)}$ for a period ranging from 10 minutes to six hours. This is according to Colwill(23) who found that the average time spent in the supermarket on a main food shopping trip was 42 minutes and that most people removed food from the chilled display within 15 minutes of coming at the shop. Although, the small percentage of respondents who lack knowledge about the characteristics of good quality meat(18.09\%), 
poultry $(8.88 \%)$, and fish $(0.00 \%)$, they

Table 2: Incidence of purchasing malpractices

\begin{tabular}{|c|c|c|}
\hline $\begin{array}{l}\text { Purchasing } \\
\text { parameter }\end{array}$ & Behavior & $\begin{array}{c}\text { Occurrences } \\
(\%)\end{array}$ \\
\hline Premises & $\begin{array}{l}\text { Cleaned environment not necessary to buy from a } \\
\text { specified store }\end{array}$ & 60.00 \\
\hline \multirow[t]{2}{*}{ Food handler } & $\begin{array}{l}\text { Cleanliness of the person handling purchased } \\
\text { item not noticed }\end{array}$ & 15.38 \\
\hline & $\begin{array}{l}\text { Purchasing continues although the improper } \\
\text { cleanliness of the food handler. }\end{array}$ & 30.76 \\
\hline Order & Specified order during purchasing not followed & 499.52 \\
\hline Quality of food & $\begin{array}{l}\text { Quality of food not a condition for purchasing } \\
\text { foods. }\end{array}$ & 43.07 \\
\hline \multirow[t]{4}{*}{$\begin{array}{l}\text { Inspection } \\
1 \text { - Meat }\end{array}$} & Good quality meat not known & 18.09 \\
\hline & Un-refrigerated meat is being purchased & 42.00 \\
\hline & Cleaning of cutting utensils not noticed. & 33.33 \\
\hline & $\begin{array}{l}\text { Previously thawed and refrozen meat is being } \\
\text { purchased. }\end{array}$ & 28.57 \\
\hline \multirow{4}{*}{$\begin{array}{l}\text { 2-Poultry } \\
\text { 3-Egg }\end{array}$} & Poultry quality not inspected & 8.88 \\
\hline & Too much egg purchased at a time & 15.23 \\
\hline & Broken egg used & 55.00 \\
\hline & $\begin{array}{l}\text { Egg cleaning and storage not a condition for } \\
\text { purchasing. }\end{array}$ & 55.39 \\
\hline \multirow[b]{3}{*}{ 5-Canned food } & $\begin{array}{l}\text { Purchased fish not chilled (not surrounded by ice } \\
\text { crystals) }\end{array}$ & 78.46 \\
\hline & Good quality fish not known & 0.00 \\
\hline & Cans not inspected before purchasing & 5.00 \\
\hline Label & $\begin{array}{l}\text { Purchasing not done according to production and } \\
\text { expiration dates. }\end{array}$ & 10.76 \\
\hline
\end{tabular}

Note: Number of subjects $=105$

continue to buy unrefrigerated meat (held at the butcher's shops out in the air) (42.00\%), $28.57 \%$ can buy frozen meat package that might contain ice crystals or thaw water indicating previous thawing and refreezing, $78.46 \%$ buy fish that might not be surrounded by ice crystals for chilling and $55.39 \%$ and 55.00 are interested to buy low price or large sized eggs and broken eggs, respectively rather than selecting cleaned and properly stored eggs. It is impossible to prepare a 
wholesome meal with contaminated or spoiled ingredients. Food supplies must be in excellent condition when they arrive home. They must be purchased, from approved sources only and examined for signs of spoilage and contamination before being used.(10)

\section{Food preparation and serving}

Now that the food has been purchased, it is essential that it be prepared and served safely. It is at this point in the flow of foods that the greatest risk for contamination and temperature abuse can occur. ${ }^{(10)}$ Table 3 illustrates the incidence of food preparation and serving malpractices.

\section{Washing/thawing}

Preparation begins by washing raw ingredients. Running water only will remove some microorganisms, but may be a first step in the cross-contamination of other foods. Most of domestic kitchens had a single sink which had to be used for all washing activities. ${ }^{(19)}$ This risk might be reduced by decreasing the $\mathrm{pH}$ during washing by dipping or soaking raw ingredients in acetic acid. About $64 \%$ of respondents used running water only. In other operations, the first step in the food preparation process is the thawing of frozen foods. The method selected to thaw frozen food and the manner in which it is carried out can spell the difference between preventing growth of microorganisms or allowing microorganisms to increase to high levels. ${ }^{(10)}$ The latter is expected to occur during thawing frozen food items among $42.85 \%$ of respondents who left frozen foods to thaw at room temperature. Higher levels of microorganisms are very well expected among $27.50 \%$ of respondents who can refreeze thawed foods.

\section{Cooking}

Less than half of respondents $(34.28 \%)$ prepared foods early in advance of serving. The action of tasting of food using a stirring spoon to test end of cooking was common by $59.04 \%$ of respondents. A 
recommended procedure to avoid any possible contamination of the food being prepared, is to ladle a small amount of the food into a small dish, tasting from that dish with a separate spoon then removing the dish and spoon to be washed. ${ }^{(10)}$ There is potential hazards of improper cooking to an internal temperature that should reaches at least $70^{\circ} \mathrm{C}$ for at least 2 minutes ${ }^{(16,19)}$ during stuffing preparation inside poultry (especially turkey) by $55.38 \%$ of respondents. Stuffing acts as insulation, further reduces heat penetrating from the oven to the interior of the bird. Rather stuffing must be cooked separately from the bird to make sure proper temperatures are reached and microorganisms are killed.(10) Consumer surveys ${ }^{(12)}$ found that most people are aware that undercooking is a cause of food poisoning and claim to always or usually serve food that is piping hot. ${ }^{(15)}$

\section{Cooling}

MAFF (1991) guides the public to cool the food as quickly as possible if intending to eat it later ${ }^{(16)}$ and consumer surreys ${ }^{(15)}$ have shown that most people (92\%) always or usually claim to eat cooked food at once, thereby avoiding potential problems with cooling, holding, and reheating food. In this study, $80.95 \%$ of the subjects delayed consuming the food they had prepared and held it at ambient temperature for more than one hour. Over half $(58 \%)$ of subjects in another study held the cooked product at ambient temperature for more than 90 minutes. ${ }^{(19)}$ There is little or no hazard of food poisoning if foods are thoroughly cooked and then eaten promptly, but as the time between cooking and eating increases, temperature control during the interim becomes of increasing importance. (22) A high percentage (86.15\%) of respondents failed to cool cooked food quickly. They tended to leave it sometimes covered at ambient temperature in the kitchen to cool. Evans et al.,(1991) found most people (72.2\%) kept their kitchens at 
between $17^{\circ} \mathrm{C}$ and $23^{\circ} \mathrm{C}$, and that many subjects held the cooked food in the original cooking container covered with a lid.(24)

\section{Reheating}

Reheating is the last line of defense in preventing food poisoning. If bacteria have survived cooking or if there has been postcooking contamination, improper cooling and prolonged storage at room temperature, the large population of bacteria that can result must be killed during reheating. ${ }^{(19)} \mathrm{A}$ considerable percentage of respondents in this study $(40.00 \%)$ tended to just warm prepared food left at ambient temperature while $45.00 \%$ of them can reheat food more than once. MAFF (1991) advice the public to reheat food only once and then until it is piping hot.(16) Surveys find that many people are aware that inadequate reheating may be a cause of food poisoning ${ }^{(13)}$ and most (98\%) believe that it is very or fairly important to reheat food only once, (15) but the behavior of the subjects in another study was to reheat the products to an internal temperature of $<74^{\circ} \mathrm{C}$ and to reheat dishes more than once. ${ }^{(19)}$

Table 3: Incidence of food preparation and serving malpractices

\begin{tabular}{|l|l|c||}
\hline $\begin{array}{l}\text { Food reparation and } \\
\text { serving parameter }\end{array}$ & \multicolumn{1}{|c|}{ Behavior } & $\begin{array}{c}\text { Occurrence } \\
(\%)\end{array}$ \\
\hline Preparation & Preparation early in advance of serving & 34.28 \\
\hline \hline $\begin{array}{l}\text { Washing raw } \\
\text { ingredients }\end{array}$ & Improper washing & 64.61 \\
\hline \hline Spoiled food & Spoiled food used & 1.53 \\
\hline \hline Thawing & Improper method of thawing frozen food items & 42.85 \\
\cline { 2 - 3 } & Refreezing of thawed food & 27.50 \\
\hline \hline Cooking & Cooked food tasted to check end of cooking & 59.04 \\
\hline \hline Stuffing & Ingredients not cooked before inserted in turkeys & 55.38 \\
\hline \hline Cooling & Improper cooling & 86.15 \\
\hline \hline Holding & $\begin{array}{l}\text { Prepared food held at room temperature for hour or } \\
\text { more }\end{array}$ & 80.95 \\
\hline \hline Reheating & Freshly prepared food mixed with leftovers & 21.53 \\
\hline
\end{tabular}


Table 4: Comparison between the score percentages of the interview questionnaire of the different age groups of the 105 respondents.

\begin{tabular}{|c|c|c|c|c|c|}
\hline \multirow{2}{*}{$\begin{array}{c}\text { Age } \\
\text { group }\end{array}$} & \multirow{2}{*}{$\begin{array}{c}\text { Percentage } \\
(\%)\end{array}$} & \multicolumn{3}{|c|}{ Parameter Score Percentage (\%) } & \multirow[t]{2}{*}{ F-value } \\
\hline & & Sanitation & Purchasing & $\begin{array}{l}\text { Food preparation } \\
\text { and serving }\end{array}$ & \\
\hline \multirow[t]{2}{*}{$20-30$} & \multirow[t]{2}{*}{26.20} & $60.02 \pm 24.53$ & $79.21 \pm 12.51$ & $59.10 \pm 20.11$ & \multirow{2}{*}{$\begin{array}{c}7.643^{*} \\
(p=0.01)\end{array}$} \\
\hline & & $(0.00-100.00)$ & $(57.14-100.00)$ & $(16.66-90.90)$ & \\
\hline \multirow[t]{2}{*}{$31-40$} & \multirow[t]{2}{*}{25.00} & $70.24 \pm 17.70$ & $80.70 \pm 13.96$ & $53.03 \pm 25.58$ & \multirow{2}{*}{$\begin{array}{c}11.290^{*} \\
(p=0.001)\end{array}$} \\
\hline & & $(50.00-100.00)$ & $(53.33-100.00)$ & $(0.00-90.00)$ & \\
\hline \multirow[t]{2}{*}{$41-50$} & \multirow[t]{2}{*}{23.80} & $61.35 \pm 21.01$ & $76.58 \pm 14.41$ & $49.44 \pm 20.20$ & \multirow{2}{*}{$\begin{array}{l}10.546^{*} \\
(p=0.001)\end{array}$} \\
\hline & & $(0.00-100.00)$ & $(49.33-100.00)$ & $(16.66-90.00)$ & \\
\hline \multirow[t]{2}{*}{$51-60$} & \multirow[t]{2}{*}{22.60} & $49.14 \pm 28.60$ & $77.74 \pm 10.32$ & $52.56 \pm 15.21$ & \multirow{2}{*}{$\begin{array}{l}10.716^{*} \\
(p<0.001\end{array}$} \\
\hline & & $(0.00-81.81)$ & $(66.66-100.00)$ & $(13.33-78.00)$ & \\
\hline \multirow[t]{2}{*}{$>60$} & \multirow[t]{2}{*}{2.40} & $50.00 \pm 70.71$ & $76.37 \pm 7.00$ & $29.39 \pm 22.71$ & \multirow{2}{*}{$\begin{array}{c}0.598 \\
(p=0.605)\end{array}$} \\
\hline & & $(0.00-100.00)$ & $(71.42-81.33)$ & $(13.33-45.45)$ & \\
\hline \multirow{2}{*}{\multicolumn{2}{|c|}{ Average }} & $60.41 \pm 24.89$ & $78.61 \pm 12.73$ & $53.17 \pm 21.06$ & \\
\hline & & $(0.00-100.00)$ & $(49.33-100.00)$ & $(0.00-90.90)$ & \\
\hline \multicolumn{2}{|l|}{ F- value } & $\begin{array}{c}2.064 \\
(p=0.093)\end{array}$ & $\begin{array}{c}0.313 \\
(p=0.868)\end{array}$ & $\begin{array}{c}1.269 \\
(P=0.289)\end{array}$ & \\
\hline
\end{tabular}

Data in columns represent the mean \pm standard deviation and the (minimum - maximum) of score percentages of the different age groups of respondents.

* Statistically significant at $\mathrm{p}<0.05$.

F test (ANOVA)

Table 5: Comparison between the score percentages of the interview questionnaire of the different educational groups of the 105 respondents.

\begin{tabular}{|c|c|c|c|c|c|}
\hline \multirow{2}{*}{$\begin{array}{c}\text { Educational } \\
\text { group }\end{array}$} & \multirow{2}{*}{$\begin{array}{c}\text { Percentage } \\
(\%)\end{array}$} & \multicolumn{3}{|c|}{ Parameter Score Percentage (\%) ${ }^{\star}$} & \multirow[b]{2}{*}{ F-value } \\
\hline & & Sanitation & Purchasing & $\begin{array}{l}\text { Food preparation } \\
\text { and serving }\end{array}$ & \\
\hline \multirow[t]{2}{*}{ High } & \multirow[t]{2}{*}{58.63} & $65.62 \pm 23.45$ & $79.84 \pm 13.40$ & $58.59 \pm 16.89$ & \multirow{2}{*}{$\begin{array}{c}17.314^{*} \\
(p<0.001)\end{array}$} \\
\hline & & $(0.00-100.00)$ & $(49.33-100.00)$ & $(16.66-90.90)$ & \\
\hline \multirow[t]{2}{*}{ Medium } & \multirow[t]{2}{*}{26.43} & $53.43 \pm 26.76$ & $82.50 \pm 12.63$ & $52.05 \pm 24.87$ & \multirow{2}{*}{$\begin{array}{c}13.056^{*} \\
(p<0.001)\end{array}$} \\
\hline & & $(0.00-100.00)$ & $(57.14-100.00)$ & $(0.00-90.00)$ & \\
\hline \multirow[t]{2}{*}{ Low } & \multirow[t]{2}{*}{9.20} & $53.98 \pm 29.00$ & $84.45 \pm 11.06$ & $38.44 \pm 11.45$ & \multirow{2}{*}{$\begin{array}{l}12.013^{*} \\
(p<0.001)\end{array}$} \\
\hline & & $(0.00-100.00)$ & $(71.42-100.00)$ & $(16.66-50.00)$ & \\
\hline \multirow[t]{2}{*}{ Absent } & \multirow[t]{2}{*}{5.74} & $64.74 \pm 12.87$ & $68.94 \pm 19.26$ & $53.96 \pm 18.32$ & \multirow{2}{*}{$\begin{array}{c}1.027 \\
(p=0.388)\end{array}$} \\
\hline & & $(50.00-77.77)$ & $(50.66-100.00)$ & $(27.27-78.00)$ & \\
\hline \multirow{2}{*}{\multicolumn{2}{|c|}{ Average }} & $61.32 \pm 24.72$ & $80.32 \pm 13.54$ & $54.73 \pm 19.59$ & \\
\hline & & $(0.00-100.00)$ & $(49.33-100.00)$ & $(0.00-90.90)$ & \\
\hline \multicolumn{2}{|c|}{ Test of significance } & $\begin{array}{c}1.677^{a} \\
(p=0.178)\end{array}$ & $\begin{array}{c}5.132^{b} \\
(p=0.162)\end{array}$ & $\begin{array}{l}10.178^{* b} \\
(p=0.017)\end{array}$ & \\
\hline
\end{tabular}

Data in columns represent the mean \pm standard deviation and the (minimum - maximum) of score percentages of the different age groups of respondents.

* Statistically significant at $p<0.05$.

a $F$ test (ANOVA)

${ }^{b}$ Chi square for Kruskal Wallis test 


\section{CONCLUSION}

This study, was based on evaluating the safety of foods prepared by some Egyptian women at their homes through interviewing 105 Egyptian women about their food safety knowledge needed to prepare safe food. The study showed that the interviewed Egyptian women lacked knowledge about the importance of frequently washing hands especially throughout operations and washing of equipment between preparations, a fact that would decrease a great potential for indirect or direct crosscontamination. Low quality ingredients are expected to be delivered at homes by almost half of respondents, who rather preferred low price ingredients. Even if they said they know the characteristics of good quality meat, poultry, and fish, they accept to buy unrefrigerated meat or fish and did not follow the safe order of purchasing dry or plant food first then animal food.
Potentially unsafe handling practices were concluded as many respondents held cooked food for prolonged periods at room temperature and many improperly cooled food by leaving it at room temperature on stove. For reheating, many respondents just warmed prepared food and reheated foods more than once. Egyptian women within different age and educational group did not differ significantly in their score percentages concerned with sanitation and purchasing. Preparation and serving score percentages differed significantly only within educational groups. On the other hand, score percentages of sanitation, purchasing, food preparation, and serving differed significantly within each of the age groups; 20-30, 31-40, $41-50$, and 51-60 and within each of the educational groups; high, medium, and low. 


\section{RECOMMENDATION}

People preparing food at home need to be

reminded of the increased risk of disease

that can arise from poor food handling

practices.

\section{REFERENCES}

1- Institute of food technologists (IFT). Scientific status summary, food borne illness: Role of home food handling practices. Food Technology. 1995; 49 (4): 119-31.

2- International Commission on Microbiological Specifications for Foods (ICMSF). Microorganisms in Foods, Book 4: Application of the Hazard Analysis Critical Control Point (HACCP) system to Ensure Microbiological Safety and Quality. Oxford: Blackwell Scientific; 1988

3- Penner K, Kramer C , Frantz G. Consumer food safety perceptions. MF774 Kansas State University Ext. Manhattan, KA: Service; 1985.

4- Williamson DM. Home food preparation practice: results of a national consumer survey, unpublished MS thesis. Ithaca, New York, NY; Cornell University; 1991.

5- Food and Drink Federation. National Food Safety Report. London: 1996.

6- Ministry of Agriculture Fisheries and Food. Keeping food cool and safe. London: The Food Safety Directorate; 1994.

7- Spriegel G. Food Safety in the home. Nutrition and Food Science;1991: 1415.

8- Bryan FL. Factors that contribute to outbreaks of foodborne disease. Journal of Food Protection.1978; 41: 816-27.
9- Mitakakis TZ, Sinclair MI, Fairley CK, Lightbody PK, leder K, Hellard ME. Food safety in family homes in Melbourne, Australia. J Food Prot. 2004; 67 (4): 818-22.

10- Food service sanitation: A certification course book. Educational Foundation of the National Restaurant Association; 1992.

11- Ackerley LM. Food Hygiene and food poisoning: a study of public perceptions, unpublished $\mathrm{PhD}$ thesis. OK: University of Birmingham, Birmingham;1990.

12- FDF. National Food Safety Report, Food and Drink Federation and the Institution of Environment Health Officers. London:. 1996.

13- Ministry of Agriculture, Fisheries and Food (MAFF). Food Hygiene: Report on a Consumer Survey, HMSO. London: 1988.

14- Spriegel G. Food safety in the home. Nutrition and Food Science; 1990: 14 15.

15- Walker A. Food Safety in the Home: A Report on ONS Omnibus Survey Data Produced on Behalf of the Department of Health, HMSO, London: 1996.

16- Ministry of Agriculture, Fisheries and Food (MAFF). Food safety: A Guide from the Food Safety Directorate, Food Sense, London: 1991.

17- FDF. National Food Safety Report. London: Food and Drink Federation and the Institution of Environment Health Officers; 1993.

18- FDF . National Food Safety Report. London: Food and Drink Federation and the Institution of Environment Health officers; 1993.

19- Worsfold D, Christopher G. Food safety behavior in the home. British Food Journal. 1997; 99(3):97-104. 
20- Marklinder IM, Lindblad M, Eriksson AM, Lindqvist $R$. Home storage temperatures and consumer handling of refrigerated foods in Sweden. J Food Prot. 2004; 67(11):2570-7.

21- Hudson PK, Hartwell HJ. Food safety awareness of older people at home: a pilot study. J R Soc Health. 2002; 122(3):165-9.

22- Johnson AE, Donkin AJ, Morgan K, Lilley JM , Neale RJ, Page RM, et al. Food safety knowledge and practice among elderly people living at home. J
Epidemiol Community Health. 1998; 52: 745-8.

23- Colwill JS. Survey of shopping habits for chilled foods. London: Campden Food and Drink Research Association Technical Memorandum No. 601; 1990 (601).

24- Evans Gl, Stanton JL, Russell SL, James SJ. Consumer Handling of Chilled Foods: A Survey of Time and Temperature Conditions. London: MAFF; 1991. 